\title{
An Iridoid Glucoside Dimer and a Non-glycosidic Iridoid from the Leaves of Lasianthus wallichii
}

\author{
Yoshio Takeda, ${ }^{*, a}$ Hideko Shimidzu, ${ }^{a}$ Kenta Mizuno, ${ }^{a}$ Sachiyo Inouchi,${ }^{a}$ Toshiya Masuda, ${ }^{a}$ \\ Eiji Hirata, ${ }^{b}$ Takakazu Shinzato, ${ }^{c}$ Mitsunori Aramoto, ${ }^{d}$ and Hideaki Otsuka ${ }^{e}$ \\ ${ }^{a}$ Faculty of Integrated Arts and Sciences, The University of Tokushima; 1-1 Minamijosanjima-cho, Tokushima 770-8502, \\ Japan: ${ }^{b}$ Faculty of Agriculture, University of the Ryukyus; 1 Senbaru, Nishihara-cho, Nakagami-gun, Okinawa 903-0213, \\ Japan: ' Yona Field, Subtropical Field Science Center, Faculty of Agriculture, University of the Ryukyus; 685 Yona, \\ Kunigami-son, Kunigami-gun, Okinawa 905-1427, Japan: ${ }^{d}$ Tropical Biosphere Research Center, University of the \\ Ryukyus; 870 Uehara, Taketomi-cho, Yaeyama-gun, Okinawa 907-1541, Japan: and ${ }^{e}$ Department of Pharmacognosy, \\ Graduate School of Biomedical Sciences, Hiroshima University; 1-2-3 Kasumi, Minami-ku, Hiroshima 734-8551, Japan. \\ Received May 13, 2002; accepted June 26, 2002
}

\begin{abstract}
A new iridoid glucoside dimer (1) and a non-glycosidic iridoid (2) was isolated together with the known compounds, asperuloside (3), paederoside (4), daphylloside (5), citroside A (6) and benzyl 6-O- $\alpha$-L-rhamnopyranosyl- $\beta$-D-glucopyranoside (7), from the leaves of Lasianthus wallichii. The structures of the new compounds were elucidated by spectroscopic and chemical evidence.
\end{abstract}

Key words Lasianthus wallichii; Rubiaceae; iridoid glucoside dimer; non-glycosidic iridoid

Genus Lasianthus is classified in the tribe Morindeae, subfamily Rubioideae (Rubiaceae). Kooiman ${ }^{1)}$ pointed out the presence of so called asperulosidic acid in almost all $\mathrm{Ru}-$ bioideae plants except for some exceptions based on the test of the extracts with the Trim and Hill reaction. ${ }^{2)}$ Although the presence of asperuloside (3) in some of plants of the genus Lasianthus was reported ${ }^{3)}$ based on the results of TLC and GC of the glycosidic fraction, few reports dealing with the constituents have appeared. In the course of studies on the constituents of the plants which are grown under a subtropical climate, we investigated the constituents of the leaves of Lasianthus wallichii (WIGHT \& ARN.) Wight (Rubiaceae) and isolated two new compounds, one of which is bisiridoid glucoside (1) and the other non-glycosidic iridoid (2), together with five known compounds: asperuloside (3), ${ }^{4}$ paederoside (4), ${ }^{5,6)}$ daphylloside $(\mathbf{5}),{ }^{7)}$ citroside A (6), ${ }^{8)}$ benzyl 6- $O$ - $\alpha$-L-rhamnopyranosyl- $\beta$-D-glucopyranoside (7). ${ }^{9)}$ This paper deals with the isolation and structure elucidation of the new compounds.

Compound 1 (1) was isolated as an amorphous powder, $[\alpha]_{\mathrm{D}}-58.4^{\circ}(\mathrm{MeOH})$ and the molecular formula was assigned as $\mathrm{C}_{36} \mathrm{H}_{44} \mathrm{O}_{22}$, based on its negative ion high resolution (HR)-FAB-MS. It showed an absorption maximum at $228 \mathrm{~nm}(\varepsilon 14120)$ in the UV spectrum. The ${ }^{1} \mathrm{H}-\mathrm{NMR}$ spectrum showed, in addition to two singlets at $\delta 2.05$ and 2.08 (each $3 \mathrm{H})$, two signals at $\delta 7.30(1 \mathrm{H}, \mathrm{d}, J=2.2 \mathrm{~Hz})$ and 7.70 $(1 \mathrm{H}, \mathrm{dd}, J=1.7,0.6 \mathrm{~Hz})$, which are characteristic of the proton on $\mathrm{C}-3$ of iridoid glucosides having a carbonyl group on C-4, two signals at $\delta 5.07(1 \mathrm{H}, \mathrm{dd}, J=9.0,0.6 \mathrm{~Hz})$ and 5.83 $(1 \mathrm{H}, \mathrm{dd}, J=0.6,0.6 \mathrm{~Hz})$ assigned to acetalic protons and two anomeric protons at $\delta 4.73(2 \mathrm{H}, \mathrm{d}, J=7.9 \mathrm{~Hz})$. Thus compound 1 was presumed to be composed of two iridoid glycoside units. The structure of the aglycone portion of one unit was shown to be the same as that of $\mathbf{3}$ (partial structure A) on the results of ${ }^{1} \mathrm{H}-{ }^{1} \mathrm{H}$ correlation spectroscopy (COSY) spectrum. Thus, starting from the signal at $\delta 7.30$ assignable to the proton on $\mathrm{C}-3$, cross peaks were followed to $\delta 3.67(\mathrm{H}-$ 5), 5.56 (H-6), 5.73 (H-7), and 4.63 and $4.72\left(\mathrm{H}_{2}-10\right)$. In contrast, starting from the signal at $\delta 3.67$, cross peaks were fol- lowed to $\delta 3.23$ (H-9) and 5.83 (H-1), successively. The structure of the aglycone of the other unit was also elucidated to be the same as that of 10-O-acetylasperulosidate (partial structure B) based on the results of ${ }^{1} \mathrm{H}-{ }^{1} \mathrm{H}$ COSY spectrum. Thus, starting from the signal at $\delta 7.70$, cross peaks were followed to the signals at $\delta 3.05(\mathrm{H}-5), 4.84(\mathrm{H}-6), 6.02(\mathrm{H}-7)$, and 4.80 and $4.94\left(\mathrm{H}_{2}-10\right)$, successively. The cross peaks were further followed to the signals at $\delta 2.66(\mathrm{H}-9)$ and 5.07 (H-1) starting from the signal at $\delta 3.05$. The ${ }^{13} \mathrm{C}-\mathrm{NMR}$ data shown in Table 1 clearly demonstrated that compound 1 is constituted from 3 unit and 10-O-acetylasperulosidate unit. Since the C-11 signal of unit B resonated in almost the same region as in $\mathbf{5}$ (Table 1), the carboxyl group at C-4 in the partial structure unit B formed an ester linkage with one of the hydroxyl group in the glucose moiety in the partial structure of unit A. Alkaline hydrolysis of compound 1 gave deacetylasperulosidic acid (8). ${ }^{11)}$ The location of the ester linkage was inferred at $O-6^{\prime}$ in unit A, because the signal assigned to $\mathrm{H}_{2}-6^{\prime}$ of that unit suffered downfield shift to $\delta 4.22$ and 4.63 and ${ }^{13} \mathrm{C}$-NMR signals of sugar portion for unit A well correspond to those of $6-O$-acylated glucose derivatives. ${ }^{10)}$ This

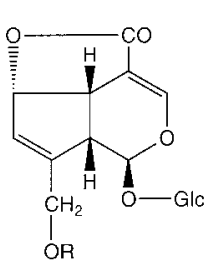

(3) $\mathrm{R}=\mathrm{COMe}$
(4) $\mathrm{R}=\mathrm{COS} \cdot \mathrm{Me}$

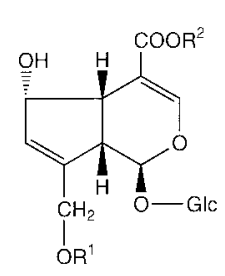

(5) $\mathbf{R}^{1}=$ COMe ; $\mathrm{R}^{2}=\mathrm{CH}_{3}$ (8) $R^{1}=R^{2}=H$

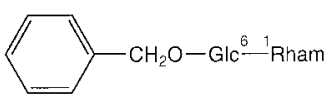

(7)

Glc : $\beta$-D-glucopyranosyl Rham : $\alpha$-L-rhamnopyranosyl 
Table $1 .{ }^{13} \mathrm{C}$-NMR Data $\left.(\delta, \mathrm{ppm})^{a}\right)$ of Compound $1(\mathbf{1})$, Asperuloside (3) and Daphylloside (5) (in $\mathrm{CD}_{3} \mathrm{OD}$ )

\begin{tabular}{|c|c|c|c|c|}
\hline \multirow{2}{*}{ Carbon } & \multicolumn{2}{|c|}{1} & \multirow{2}{*}{3} & \multirow{2}{*}{5} \\
\hline & Unit A & Unit B & & \\
\hline 1 & 93.4 & 101.5 & 93.3 & 101.3 \\
\hline 3 & 150.2 & 155.8 & 150.3 & 155.4 \\
\hline 4 & 106.4 & 108.2 & 106.2 & 108.1 \\
\hline 5 & 37.5 & 42.6 & 37.5 & 42.4 \\
\hline 6 & 86.3 & 75.6 & 86.3 & 75.4 \\
\hline 7 & 129.3 & 132.0 & 128.9 & 131.8 \\
\hline 8 & 144.2 & 146.1 & 144.2 & 146.0 \\
\hline 9 & 45.4 & 46.4 & 45.2 & 46.2 \\
\hline 10 & 61.9 & 63.7 & 60.9 & 63.8 \\
\hline 11 & 172.1 & 168.7 & 172.2 & 169.3 \\
\hline \multirow[t]{2}{*}{ Ac } & 20.8 & 20.8 & 20.7 & 20.8 \\
\hline & 172.5 & 172.5 & 172.5 & 172.5 \\
\hline $1^{\prime}$ & 100.1 & 100.7 & 100.0 & 100.6 \\
\hline $2^{\prime}$ & 74.7 & 75.0 & 74.6 & 74.9 \\
\hline $3^{\prime}$ & 78.0 & 78.6 & 78.3 & 78.6 \\
\hline $4^{\prime}$ & $71.7^{b)}$ & $71.8^{b)}$ & 71.5 & 71.5 \\
\hline $5^{\prime}$ & 76.0 & 77.9 & 77.8 & 77.9 \\
\hline $6^{\prime}$ & 64.4 & 63.1 & 62.8 & 63.0 \\
\hline
\end{tabular}

a) The assignments are based on ${ }^{1} \mathrm{H}-\mathrm{COSY}$, HSQC, HMBC and comparisons of spectra of closely related compounds. b) May be interchanged.

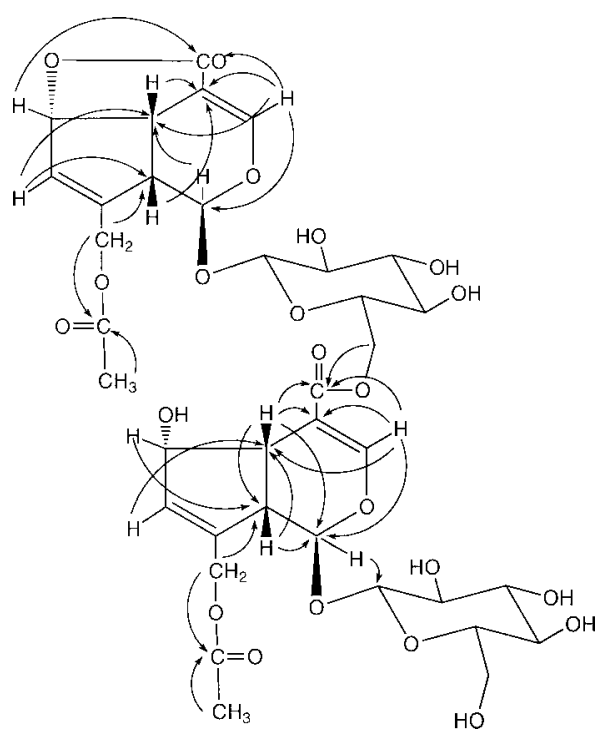

Fig. 1. The Results of HMBC Spectrum of Compound $1(\mathbf{1})(\mathrm{J}=8 \mathrm{~Hz})$

presumption was confirmed by the facts that the proton signals of $\mathrm{H}_{2}-6^{\prime}$ of unit $\mathrm{A}$ crossed peaks with the ester carbonyl signal at $\delta 168.7$ (C-11 in unit B) which crossed peaks with the signal due to $\mathrm{H}-3_{\mathrm{B}}$ and $\mathrm{H}-5_{\mathrm{B}}$ in the unit $\mathrm{B}$ in the heteroatom multiple bond correlation (HMBC) spectrum, the results of which are shown in Fig. 1. Thus, the structure of compound 1 was elucidated as shown in Fig. 1.

Compound 2 (2) was isolated as a syrup, $[\alpha]_{\mathrm{D}}-30.6^{\circ}$ (MeOH). The molecular formula was assigned as $\mathrm{C}_{10} \mathrm{H}_{14} \mathrm{O}_{5}$ based on its negative ion HR-FAB-MS. The compound was transparent above $220 \mathrm{~nm}$ in the UV spectrum and showed absorptions of hydroxyl groups $\left(3332 \mathrm{~cm}^{-1}\right)$ and a five-membered lactone group $\left(1747 \mathrm{~cm}^{-1}\right)$ in the IR spectrum. The ${ }^{13} \mathrm{C}-\mathrm{NMR}$ spectrum (Table 2) showed only ten carbon signals composed of four methylene groups, three of which bear a
Table 2. ${ }^{1} \mathrm{H}$ - and ${ }^{13} \mathrm{C}$-NMR Data $(\delta)$ of Compound $2(\mathbf{2})$ (in $\left.\mathrm{CD}_{3} \mathrm{OD}\right)$

\begin{tabular}{rrl}
\hline \hline Atom & \multicolumn{1}{c}{$\delta_{\mathrm{C}}$} & \multicolumn{1}{c}{$\delta_{\mathrm{H}}$} \\
\hline 1 & 58.5 & $4.19(2 \mathrm{H}, \mathrm{brs})$ \\
3 & 63.5 & $3.86(\mathrm{dd}, J=10.6,3.7 \mathrm{~Hz})$ \\
& & $3.93(\mathrm{dd}, J=10.6,4.1 \mathrm{~Hz})$ \\
4 & 48.7 & $2.83(\mathrm{ddd}, J=6.4,4.1,3.7 \mathrm{~Hz})$ \\
5 & 53.2 & $3.67(\mathrm{~m})$ \\
6 & 83.2 & $5.11(\mathrm{td}, J=6.6,1.1 \mathrm{~Hz})$ \\
7 & 41.9 & $2.71(\mathrm{~d}, J=18.1 \mathrm{~Hz})$ \\
& & $2.91(\mathrm{ddd}, J=18.1,6.6,1.1 \mathrm{~Hz})$ \\
8 & 138.5 & \\
10 & 137.4 & $4.15(\mathrm{brd}, J=13.2 \mathrm{~Hz})$ \\
11 & 57.1 & $4.29(\mathrm{brd}, J=13.2 \mathrm{~Hz})$ \\
& 180.8 & \\
\hline
\end{tabular}

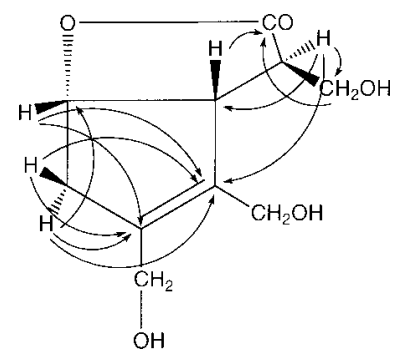

Fig. 2. The Results of HMBC Spectrum of Compound $2(2)(J=8 \mathrm{~Hz})$

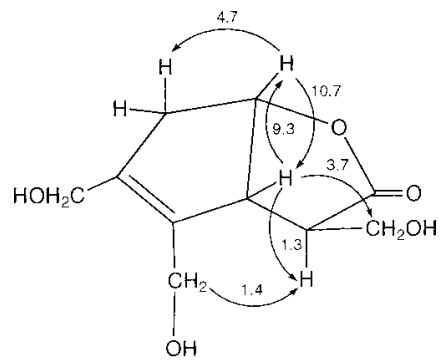

Fig. 3. The Results of NOE Experiments for Compound 2 (2)

hydroxyl group; three methine groups, one of which bears an carbonyloxy group; a tetrasubstituted double bond and a lactonic carbon atom. Analysis of one-dimensional spectra and ${ }^{1} \mathrm{H}$-COSY, heteronuclear single quantum coherence (HSQC) and HMBC (Fig. 2) spectra led to the proposed structure for compound 2 and enabled the complete assignments of ${ }^{1} \mathrm{H}$ and ${ }^{13} \mathrm{C}$-NMR signals. The observed coupling constant in the ${ }^{1} \mathrm{H}$-NMR spectra and the co-occurrence of $\mathbf{3}$ which might be a possible biogenetic precursor strongly suggested that chiral centers at C-5 and 6 are $R$ and $S$-configurations. The results of differential nuclear Overhauser effect (NOE) experiments shown in Fig. 3 and CD spectrum support the above presumption and the stereochemistry at C-4 is $R$-configuration. ${ }^{12)}$ Thus, the structure of compound 2 was elucidated as shown in Fig. 2.

\section{Experimental}

Optical rotations were measured on a JASCO DIP-360 digital polarimeter. IR spectra were measured on a Perkin-Elmer IR spectrometer and UV spectra on a JASCO V-530 SR spectrophotometer. ${ }^{1} \mathrm{H}$ - and ${ }^{13} \mathrm{C}-\mathrm{NMR}$ spectra were taken on a JEOL JNM EX-400 or $\alpha-400$ spectrometer at 400 and $100 \mathrm{MHz}$, respectively, with tetramethylsilane as an internal standard. HR- 
FAB-MS were performed on a JEOL JMS SX-102 spectrometer with polyethylene glycol-400 as a matrix. Column chromatography was performed on Diaion HP-20 (Mitsubishi Kagaku Co., Ltd., Tokyo), silica gel 60 (230400 mesh, Merck), and octadecyl silica (ODS) gel (Cosmosil 75 $\mathrm{C}_{18}$-OPN, Nacalai Tesque, Kyoto), and TLC was performed on precoated silica gel plates $60 \mathrm{~F}_{254}(0.25 \mathrm{~mm}$ in thickness, Merck). HPLC was performed on ODS gel (Cosmosil $10 \mathrm{C}_{18}$, Nacalai Tesque, Kyoto, $\phi=20 \mathrm{~mm}, \mathrm{~L}=250 \mathrm{~mm}$ ) with a mixture of $\mathrm{H}_{2} \mathrm{O}$ and $\mathrm{MeOH}$ at the flow rate of $6 \mathrm{ml} \mathrm{min}^{-1}$ and the eluate was monitored by UV.

Plant Material Plant material was collected in Kunigami-son, Kunigami-gun and Taketomi-cho, Yaeyama-gun, Okinawa Prefecture in July, 1998 and in October, 2000, respectively, and identified as Lasianthus wallichii (Wight \& Arn.) Wight by one (T.S.) of the authors . Voucher specimens (98-LW-Okinawa-0709 and 00-LW-Okinawa-1004) were deposited in the Herbarium of the Department of Pharmacognosy, Division of Medicinal Chemistry, Graduate School of Biomedical Sciences, Hiroshima University. In this report, we used the sample collected in Kunigami-gun, since the TLC pattern of $n-\mathrm{BuOH}$ soluble fractions obtained from both samples is the same.

Extraction and Isolation Dried leaves $(3.9 \mathrm{~kg})$ of $L$. wallichii were extracted with $\mathrm{MeOH}(721)$ at room temperature for 2 weeks. Extraction was repeated once in the same manner. The combined methanolic extract was concentrated in vacuo. The residue was dissolved in $90 \% \mathrm{MeOH}(1.11)$ and the solution was washed with $n$-hexane $(11 \times 3)$. The $90 \% \mathrm{MeOH}$ layer was concentrated in vacuo. The residue was suspended in $\mathrm{H}_{2} \mathrm{O}$ and the suspension was extracted with EtOAc $(11 \times 3)$. The aqueous layer was extracted with $n$ - $\mathrm{BuOH}(11 \times 3)$. The $n$ - $\mathrm{BuOH}$ extract was evaporated in vacuo to give a residue $(70.5 \mathrm{~g})$.

The residue was chromatographed on Diaion HP-20 $(70 \mathrm{~mm}$ in diameter and $445 \mathrm{~mm}$ in length). Adsorbed material was eluted successively with $\mathrm{H}_{2} \mathrm{O}-\mathrm{MeOH}$ with a stepwise increase of $\mathrm{MeOH}$ content. Three and one-half liters of $0 \%, 20 \%, 40 \%$ and $60 \% \mathrm{MeOH}$ in $\mathrm{H}_{2} \mathrm{O}$ and $\mathrm{MeOH}$ were eluted successively, and $500 \mathrm{ml}$ fractions were collected. The residue $(2.62 \mathrm{~g})$ of fractions $11-14$ was subjected to silica gel $(55 \mathrm{~g})$ column chromatography. Five hundred milliliters of each of $\mathrm{CHCl}_{3}$ and $\mathrm{CHCl}_{3}-\mathrm{MeOH}(97: 3,19: 1,9: 1$, $22: 3,17: 3,4: 1,3: 1,7: 3)$ were eluted successively. The eluate $(520 \mathrm{mg})$ from $5-10 \% \mathrm{MeOH}-\mathrm{CHCl}_{3}$ which contained a spot $(R f 0.30$, solvent: $\mathrm{CHCl}_{3}-\mathrm{MeOH}-\mathrm{H}_{2} \mathrm{O} 15: 6: 1$ ) on TLC was separated by HPLC (solvent: $\mathrm{MeOH}-\mathrm{H}_{2} \mathrm{O} 1: 9$, detection $\left.210 \mathrm{~nm}\right)$ to give compound $2(94.7 \mathrm{mg})$ as a viscous gum.

The residue (10.1 g) of fractions 15-24 of Diaion HP-20 column was chromatographed over silica gel $(500 \mathrm{~g})$. Three liters of $\mathrm{CHCl}_{3}$ and $\mathrm{CHCl}_{3}-$ $\mathrm{MeOH}(97: 3,19: 1,93: 7,9: 1,22: 3,17: 3,4: 1,3: 1,7: 3)$ were eluted successively. From the eluate of $\mathrm{CHCl}_{3}-\mathrm{MeOH}(9: 1), 300 \mathrm{ml}$ fractions were collected. An aliquot $(300 \mathrm{mg})$ of the residue $(863 \mathrm{mg})$ from fractions $11-$ 16 was separated by HPLC (solvent: $\mathrm{MeOH}-\mathrm{H}_{2} \mathrm{O} 3: 7$; detection $210 \mathrm{~nm}$ ) to give asperuloside (3) $(23.2 \mathrm{mg})$ and citroside A (6) $(14.4 \mathrm{mg})$. Fractions $17-21$ gave a residue $(742 \mathrm{mg})$, an aliquot $(152 \mathrm{mg})$ of which was separated by HPLC (solvent: $\mathrm{MeOH}-\mathrm{H}_{2} \mathrm{O} 7: 13$; detection $210 \mathrm{~nm}$ ) to give benzyl alcohol $\quad 6^{\prime}-\alpha$-L-rhamnopyranosyl- $\beta$-D-glucopyranoside (7) (19.6 mg). An aliquot $(199 \mathrm{mg}$ ) of the residue $(578 \mathrm{mg}$ ) was separated by HPLC (solvent: $\mathrm{MeOH}-\mathrm{H}_{2} \mathrm{O} 3: 7$; detection $210 \mathrm{~nm}$ ) to give another aliquot of asperuloside (3) $(18.6 \mathrm{mg})$ and benzyl $6-O-\alpha$-L-rhamnopyranosyl- $\beta$-D-glucopyranoside (7) $(23.3 \mathrm{mg})$.

Fractions 25-32 of Diaion HP-20 column chromatography gave a residue $(33.2 \mathrm{~g})$ which was chromatographed over silica gel $(1 \mathrm{~kg})$ with $\mathrm{CHCl}_{3}-\mathrm{MeOH}$ as eluent with increasing amounts of $\mathrm{MeOH}$ content $\mathrm{CHCl}_{3}$ (4.51), $\mathrm{CHCl}_{3}-\mathrm{MeOH}$ (9:1, 4.51), $\mathrm{CHCl}_{3}-\mathrm{MeOH}$ (22:3, 4.51), $\mathrm{CHCl}_{3}-$ $\mathrm{MeOH}(17: 3,6.51)$, and $\mathrm{CHCl}_{3}-\mathrm{MeOH}(4: 1,5.51)$ were eluted successively, $500 \mathrm{ml}$ fractions were collected. Fractions $19-22$ gave a residue $(698 \mathrm{mg})$, an aliquot $(110 \mathrm{mg})$ of which was separated by HPLC (solvent: $\mathrm{MeOH}-\mathrm{H}_{2} \mathrm{O} 7: 13$, detection $\left.230 \mathrm{~nm}\right)$ to give paederoside (4) $(19.7 \mathrm{mg})$ and daphylloside $(5)(6.3 \mathrm{mg})$. Fractions $23-25$ gave a residue $(615 \mathrm{mg})$. An aliquot $\left(100 \mathrm{mg}\right.$ ) was separated by HPLC (solvent: $\mathrm{MeOH}-\mathrm{H}_{2} \mathrm{O}$ 7:13, detection $230 \mathrm{~nm})$ to give $\mathbf{3}(12.4 \mathrm{mg}), \mathbf{4}(11.1 \mathrm{mg})$ and $\mathbf{5}(8.1 \mathrm{mg})$. Fractions 35- 40 gave a residue $(4.20 \mathrm{~g})$ which was chromatographed over ODS gel
( $45 \mathrm{~mm}$ in diameter and $470 \mathrm{~mm}$ in length). Adsorbed material was eluted with $\mathrm{H}_{2} \mathrm{O}-\mathrm{MeOH}$ with a stepwise increase of $50 \% \mathrm{MeOH}$ content $(4.51)$ and $60 \% \mathrm{MeOH}$ (4.51) eluted successively, collecting $100 \mathrm{ml}$ fractions. Fractions $6-7$ gave a residue $(1.07 \mathrm{~g})$ which was further separated by silica gel $(55 \mathrm{~g})$ column chromatography with $\mathrm{CHCl}_{3}-\mathrm{MeOH}$ as eluent with an increasing amount of $\mathrm{MeOH}$ in $\mathrm{CHCl}_{3}$ and finally by HPLC (solvent: $\mathrm{MeOH}-\mathrm{H}_{2} \mathrm{O}$ $7: 13$, detection $230 \mathrm{~nm}$ ) to give compound 1 (1) $(36.3 \mathrm{mg})$.

The known compounds isolated, asperuloside (3), paederoside (4), daphylloside (5), citroside A (6) and benzyl 6- $O$ - $\alpha$-L-rhamnopyranosyl- $\beta$-Dglucopyranoside (7) were identified with authentic samples by direct comparison or by comparison of their spectral data with those reported. The physical properties of the new compounds are as follows.

Compound 1 (1): an amorphous powder, $[\alpha]_{\mathrm{D}}^{27}-58.4^{\circ}(c=0.66, \mathrm{MeOH})$. UV $\lambda_{\max }(\mathrm{MeOH}) \mathrm{nm}(\varepsilon): 228(14120)$. IR $v_{\max }\left(\right.$ film) $\mathrm{cm}^{-1}: 3382,1732$, 1658, 1633, 1257, 1053, 1026. ${ }^{1} \mathrm{H}-\mathrm{NMR}\left(\mathrm{CD}_{3} \mathrm{OD}\right): 2.05,2.08$ (each $3 \mathrm{H}, \mathrm{s}$, $2 \times \mathrm{OAc}), 2.66(1 \mathrm{H}, \mathrm{ddd}, J=8.2,8.2,0.6 \mathrm{~Hz}, \mathrm{H}-9 \mathrm{~B}), 3.05(1 \mathrm{H}, \mathrm{ddd}, J=8.2$, $\left.6.0,1.7 \mathrm{~Hz}, \mathrm{H}-5_{\mathrm{B}}\right), c a .3 .23\left(\mathrm{H}-9_{\mathrm{A}}\right), 3.61\left(1 \mathrm{H}, \mathrm{dd}, J=11.7,4.0 \mathrm{~Hz}, \mathrm{H}_{1}-6_{\mathrm{B}}^{\prime}\right)$, $3.60-3.66\left(2 \mathrm{H}, \mathrm{m}, \mathrm{H}-5_{\mathrm{A}}^{\prime}, \mathrm{H}-5_{\mathrm{B}}^{\prime}\right), 3.67\left(1 \mathrm{H}\right.$, ddd, $\left.J=6.5,6.5,2.2 \mathrm{~Hz}, \mathrm{H}-5_{\mathrm{A}}\right)$, $3.85\left(1 \mathrm{H}, \mathrm{dd}, J=11.9,1.8 \mathrm{~Hz}, \mathrm{H}_{1}-6_{\mathrm{B}}^{\prime}\right), 4.22\left(1 \mathrm{H}, \mathrm{dd}, 11.9,6.2 \mathrm{~Hz}, \mathrm{H}_{1}-6_{\mathrm{A}}^{\prime}\right)$, $4.63\left(1 \mathrm{H}, \mathrm{dd}, J=11.9,2.2 \mathrm{~Hz}, \mathrm{H}_{1}-6_{\mathrm{A}}^{\prime}\right), 4.63\left(1 \mathrm{H}, \mathrm{dd}, J=14.1,1.2 \mathrm{~Hz}, \mathrm{H}_{1}-\right.$ $\left.10_{\mathrm{A}}\right), 4.72\left(1 \mathrm{H}, \mathrm{dd}, J=14.1,1.2 \mathrm{~Hz}, \mathrm{H}_{1}-10_{\mathrm{A}}\right), 4.73\left(2 \mathrm{H}, \mathrm{d}, J=7.9 \mathrm{~Hz}, \mathrm{H}-1_{\mathrm{A}}^{\prime}\right.$ and $\left.\mathrm{H}-1_{\mathrm{B}}^{\prime}\right), 4.80\left(1 \mathrm{H}, \mathrm{dd}, J=15.0,1.8 \mathrm{~Hz}, \mathrm{H}_{1}-10_{\mathrm{B}}\right), 4.84(1 \mathrm{H}, \mathrm{dd}, J=6.0$, $\left.2.6 \mathrm{~Hz}, \mathrm{H}-6_{\mathrm{B}}\right), 4.94\left(1 \mathrm{H}, \mathrm{dd}, J=15.0,1.8 \mathrm{~Hz}, \mathrm{H}_{1}-10_{\mathrm{B}}\right), 5.07(1 \mathrm{H}, \mathrm{dd}, J=9.0$, $\left.0.6 \mathrm{~Hz}, \mathrm{H}-1_{\mathrm{B}}\right), 5.56\left(1 \mathrm{H}, \mathrm{dt}, J=6.5,1.7 \mathrm{~Hz}, \mathrm{H}-6_{\mathrm{A}}\right), 5.73\left(1 \mathrm{H}, \mathrm{m}, \mathrm{H}-7_{\mathrm{A}}\right), 5.83$ $\left(1 \mathrm{H}, \mathrm{d}, J=0.6 \mathrm{~Hz}, \mathrm{H}-1_{\mathrm{A}}\right), 6.02\left(1 \mathrm{H}, \mathrm{brd}, J=1.8 \mathrm{~Hz}, \mathrm{H}-7_{\mathrm{B}}\right), 7.30(1 \mathrm{H}, \mathrm{d}$, $\left.J=2.2 \mathrm{~Hz}, \mathrm{H}-3_{\mathrm{A}}\right), 7.70\left(1 \mathrm{H}, \mathrm{dd}, J=1.7,0.6 \mathrm{~Hz}, \mathrm{H}-3_{\mathrm{B}}\right) .{ }^{13} \mathrm{C}-\mathrm{N} M R$ : see Table 1. HR-FAB-MS (negative) $m / z: 827.2258[\mathrm{M}-\mathrm{H}]^{-}$(Calcd for $\mathrm{C}_{36} \mathrm{H}_{43} \mathrm{O}_{22}$ : 827.2246).

Compound 2 (2): A viscous syrup, $[\alpha]_{\mathrm{D}}^{28}-30.6^{\circ}(c=0.72, \mathrm{MeOH})$. IR $v_{\max }\left(\right.$ film) $\mathrm{cm}^{-1}: 3332,1747,1362,1192,1061,991 .{ }^{1} \mathrm{H}$ - and ${ }^{13} \mathrm{C}-\mathrm{NMR}$ : see Table 2. CD $\lambda_{\max }(\mathrm{MeOH}) \mathrm{nm}(\Delta \varepsilon): 286(-0.013), 218(+1.61)$. HR-FABMS (negative) $m / z: 213.0783[\mathrm{M}-\mathrm{H}]^{-}\left(\right.$Calcd for $\left.\mathrm{C}_{10} \mathrm{H}_{13} \mathrm{O}_{5}: 213.0763\right)$.

Alkaline Hydrolysis of Compound 1 (1) $1(13.1 \mathrm{mg})$ was dissolved in $0.5 \mathrm{~N} \mathrm{NaOH}$ aqueous solution $(1 \mathrm{ml})$ and the solution was stirred for $4.5 \mathrm{~h}$ at room temperature. The solution was neutralized with an ion-exchange resin, Amberlite IR-120B (H-form). The ion exchange resin was filtered off and the filtrate was concentrated in vacuo to give $\mathbf{8}(10.5 \mathrm{mg}) .{ }^{11}$

Acknowledgements The authors are grateful to the Cooperative Center of the University of Tokushima and the Analytical Center of Molecular Medicine, Graduate School of Biomedical Sciences, Hiroshima University for providing the facilities for recording the NMR spectra.

\section{References}

1) Kooiman P., Acta Bot. Neerl., 18, 124-137 (1969).

2) Trim A. R., Hill R., Biochem. J., 50, 310-319 (1952).

3) Inouye H., Takeda Y., Nishimura H., Kanomi A., Okuda T., Puff C., Phytochemistry, 27, 2591-2598 (1988).

4) Briggs L. H., Cain B. F., Le Quesne P. W., Shoolery J. N., Tetrahedron Lett., 1963, 69-74 (1963).

5) Inouye H., Inouye S., Shimokawa N., Okigawa M., Tetrahedron Lett., 1968, 683-688 (1968).

6) Kapadia G. J., Shukla Y. N., Bose A. K., Fujiwara H., Lloyd H. A., Tetrahedron Lett., 1979, 1937-1938 (1979).

7) Inouye H., Ueda S., Hirabayashi M., Shimokawa N., Yakugaku Zasshi, 86, 943-947 (1966).

8) Umehara K., Hattori I., Miyase T., Ueno A., Hara S., Kageyama C., Chem. Pharm. Bull., 36, 5004-5008 (1988).

9) De Tommasi N., Rastrelli L., Cumanda J., Speranza G., Pizza C., Phytochemistry, 42, 163-167 (1996).

10) Garcia J., Lavaitte S., Gey C., Phytochemistry, 28, 2199-2201 (1989).

11) Inouye H., Okigawa M., Shimokawa N., Chem. Pharm. Bull., 17, 1949-1954 (1969).

12) Jennings J. P., Klyne W., Scopes P. M., J. Chem. Soc., 1965, 72117229 (1965). 